\title{
Analysis of the Interphase on Carbon Black Formed in High Voltage Batteries
}

\author{
Younesi, Reza; Christiansen, Ane Sælland; Scipioni, Roberto; Ngo, Duc-The; Simonsen, Søren \\ Bredmose; Edström, Kristina; Hjelm, Johan; Norby, Poul
}

Published in:

Journal of The Electrochemical Society

Link to article, DOI:

10.1149/2.0761507jes

Publication date:

2015

Document Version

Publisher's PDF, also known as Version of record

Link back to DTU Orbit

Citation (APA):

Younesi, R., Christiansen, A. S., Scipioni, R., Ngo, D-T., Simonsen, S. B., Edström, K., Hjelm, J., \& Norby, P. (2015). Analysis of the Interphase on Carbon Black Formed in High Voltage Batteries. Journal of The Electrochemical Society, 162(7), A1289-A1296. https://doi.org/10.1149/2.0761507jes

\section{General rights}

Copyright and moral rights for the publications made accessible in the public portal are retained by the authors and/or other copyright owners and it is a condition of accessing publications that users recognise and abide by the legal requirements associated with these rights.

- Users may download and print one copy of any publication from the public portal for the purpose of private study or research.

- You may not further distribute the material or use it for any profit-making activity or commercial gain

- You may freely distribute the URL identifying the publication in the public portal 


\title{
Analysis of the Interphase on Carbon Black Formed in High Voltage Batteries
}

\author{
Reza Younesi, ${ }^{\mathrm{a}, *, \mathrm{z}}$ Ane Sælland Christiansen, ${ }^{\mathrm{a}}$ Roberto Scipioni, ${ }^{\mathrm{a}}$ Duc-The Ngo, ${ }^{\mathrm{a}}$ \\ Søren Bredmose Simonsen, ${ }^{\text {a,* }}$ Kristina Edström, ${ }^{\mathrm{b}, *}$ Johan Hjelm, ${ }^{\text {a,* }}$ and Poul Norby ${ }^{\mathrm{a}}$
}

${ }^{a}$ Department of Energy Conversion and Storage, Technical University of Denmark, DK-4000 Roskilde, Denmark

${ }^{b}$ Department of Chemistry, Ångström Laboratory, Uppsala University, SE-751 21 Uppsala, Sweden

\begin{abstract}
Carbon black (CB) additives commonly used to increase the electrical conductivity of electrodes in Li-ion batteries are generally believed to be electrochemically inert additives in cathodes. Decomposition of electrolyte in the surface region of CB in Li-ion cells at high voltages up to $4.9 \mathrm{~V}$ is here studied using electrochemical measurements as well as structural and surface characterizations. $\mathrm{LiPF}_{6}$ and $\mathrm{LiClO}_{4}$ dissolved in ethylene carbonate:diethylene carbonate (1:1) were used as the electrolyte to study irreversible charge capacity of CB cathodes when cycled between $4.9 \mathrm{~V}$ and $2.5 \mathrm{~V}$. Synchrotron-based soft X-ray photoelectron spectroscopy (SOXPES) results revealed spontaneous partial decomposition of the electrolytes on the $\mathrm{CB}$ electrode, without applying external current or voltage. Depth profile analysis of the electrolyte/cathode interphase indicated that the concentration of decomposed species is highest at the outermost surface of the CB. It is concluded that carboxylate and carbonate bonds (originating from solvent decomposition) and $\mathrm{LiF}$ (when $\mathrm{LiPF}_{6}$ was used) take part in the formation of the decomposed species. Electrochemical impedance spectroscopy measurements and transmission electron microscopy results, however, did not show formation of a dense surface layer on $\mathrm{CB}$ particles.

(C) The Author(s) 2015. Published by ECS. This is an open access article distributed under the terms of the Creative Commons Attribution 4.0 License (CC BY, http://creativecommons.org/licenses/by/4.0/), which permits unrestricted reuse of the work in any medium, provided the original work is properly cited. [DOI: 10.1149/2.0761507jes] All rights reserved.
\end{abstract}

Manuscript submitted December 23, 2014; revised manuscript received April 9, 2015. Published April 16, 2015.

The growth of earth's population with concomitant increase in energy consumption require development of renewable energy conversion technologies coupled with advanced energy storage systems like lithium batteries. ${ }^{1,2}$ In order to increase the power density in Li-ion batteries, much research is focused on developing cathode materials that can operate at high voltages (above $4.5 \mathrm{~V}$ vs. $\mathrm{Li} / \mathrm{Li}^{+}$) with a high capacity, high cycling stability, and good rate capability. ${ }^{3-5}$ However, at high voltages, all the components of positive electrodes including the Al current collector, polymer binders, conductive additives, and other possible additives have an increased risk of degradation. In addition, one of the main issues with high voltage batteries is the instability of common aprotic electrolytes at voltage above $4.5 \mathrm{~V} .^{6,7}$ The stability of the electrolyte/cathode interphase is related to the chemistry of electrolyte solvents and salts and also to the chemistry of the components of the cathode.

Carbon black (CB) additives are one of the main constituents of cathodes, added to increase the electrical percolation and thus the electronic conductivity. ${ }^{8,9}$ Though the weight percentage of $\mathrm{CB}$ in commercial batteries is generally very small, it composes a rather large part of the internal surface area of a cathode due to its small particle size $(\approx 50 \mathrm{~nm})$, low density, and high surface area. CBs are generally thought of being an electrochemically inert additive in cathodes, but few studies have investigated the role of CBs at high voltages and have indicated that $\mathrm{CBs}$ exhibit irreversible electrochemical reactions resulting in appreciable irreversible charge capacities. ${ }^{10-18}$ This charge capacity is attributed to oxidation reactions, anodic degradation of aprotic electrolytes on the surface of $\mathrm{CBs}$, side reactions involving binder and salt, and intercalation of anions such as $\mathrm{PF}_{6}{ }^{-}$(partly reversible) and solvent molecules into graphitic layers. ${ }^{10-19}$ The oxidation voltage, decomposition products, and possible formation of a surface layer are dependent on the chemistry of electrolyte and the surface area and the surface functional groups of CBs. ${ }^{10-14}$ This is similar, but not identical, to the concept of formation of solid electrolyte interphase (SEI) on anodes. This SEI-like layer is often referred to as a solid permeable interphase (SPI) ${ }^{20}$ or cathode electrolyte interphase $(\mathrm{CEI})^{21}$ and can ideally prevent further parasitic reactions between electrolyte and cathode materials. According to La Mantia et al. the oxidation of surface active groups occurs around 4.5-4.6 V. ${ }^{12}$ They showed that the first charge capacity is dependent on the charge rate, which could indicate the formation of a SPI layer. This surface layer

*Electrochemical Society Active Member.

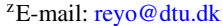

was suggested to be made of $\mathrm{Li}_{2} \mathrm{CO}_{3}, \mathrm{LiF}$, and polycarbonates, but was not analyzed to prove. ${ }^{12}$ In two recent studies Demeaux et al. and Syzdek et al. suggested decomposition products from the electrolyte on the surface of carbon particles at high voltages using FT-IR. ${ }^{11,14}$ A surface layer of decomposed electrolyte formed on carbon particles can decrease electronic conductivity, and thus, hinder the overall performance of the cathode. ${ }^{22}$

The aim of this work is to study parasitic reactions and possible formation of a surface layer on Super $\mathrm{P}$, as one of the most common $\mathrm{CB}$, in cathodes during the first few cycles at high voltages in Li-ion cells with two different electrolyte salts, $\mathrm{LiPF}_{6}$ and $\mathrm{LiClO}_{4}$. The surface layer on cathodes can be very thin, and thus, difficult to analyze by SEM, XRD ${ }^{14}$ or conventional X-ray photoelectron spectroscopy (XPS). Therefore, we used synchrotron-based soft X-ray photoelectron spectroscopy (SOXPES), which is one of the most powerful techniques for studying the outermost surface of compounds, to analyze the surface of CBs. We chose to use relatively low excitation photon energies to detect both crystalline and/or amorphous chemical compounds at shallow depths from the surfaces of the cathodes. Tuning the photon energies, we could achieve a nondestructive depth profiling of the surface layer. In addition electrochemical impedance spectroscopy (EIS), transmission electron microscopy (TEM) and energy-dispersive $\mathrm{X}$-ray spectroscopy (EDS) were used to characterize the change in morphology, structure, and chemistry of CB before and after charging to high voltages.

\section{Experimental}

Li-ion cells were assembled in a "Coffee-bag" (pouch cell) configuration ${ }^{23}$ using carbon black electrodes as the positive electrode, $\mathrm{Li}$ metal as the negative electrode, and two layers of Celgard 2500 (Monolayer Polypropylene) membrane (dried at $60^{\circ} \mathrm{C}$ overnight) as the separator. Cathodes were prepared by mixing Super P carbon black (purchased from Erachem Comilog N.V.) with Kynar binder (Kynar Flex 2801, Arkema) dissolved in (N-Methyl-2-Pyrrolidone) and casting on $\mathrm{Al}$ foil. The ratio of carbon:binder was $70: 30$ by weight. The electrodes were dried at $120^{\circ} \mathrm{C}$ overnight and were cut to discs of $10 \mathrm{~mm}$ in diameter. A total mass of $0.42 \mathrm{mg}$ Super P was used for each electrode. The electrolyte mixture consisted of $1 \mathrm{M}$ of either $\mathrm{LiPF}_{6}$ or $\mathrm{LiClO}_{4}$ salts dissolved in EC:DEC (vol. 1:1), where EC is ethylene carbonate and DEC is diethyl carbonate purchased from BASF. $200 \mu 1$ of electrolyte were added to each cell. The electrochemical characterizations were performed using a BioLogic VMP3 

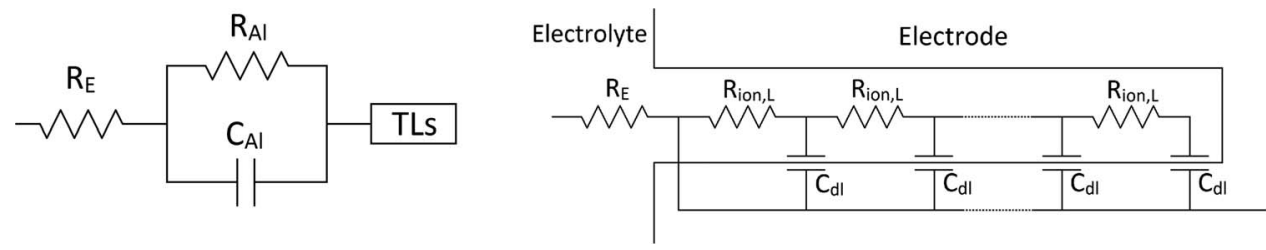

Figure 1. Equivalent circuit used for the analysis of the impedance spectra (right) including equivalent circuit of a pore described by a transmission line (left).

multichannel analyzer. A constant current of $5 \mu \mathrm{A}$ yielding the current density of about $6.4 \mu \mathrm{A} . \mathrm{cm}^{-2}$ and voltage limits of either $4.9-2.5 \mathrm{~V}$ or 4.3-2.5 V were applied for cycling cells used for SOXPES analysis. For comparison, identical cells were assembled and stored for 3 days without applying external current or voltage (hereafter referred to as "stored" electrodes). Similar cells were assembled and cycled between $5.2 \mathrm{~V}$ and $2.5 \mathrm{~V}$ for TEM and EDS analysis. Electrochemical impedance spectroscopy (EIS) measurements were performed in a three-electrode EL-CELL ECC-Combi using lithium metal as counter and reference electrodes. The cell was assembled inside the glove box using glass fiber separator (and $200 \mu 1$ electrolyte solution. EIS measurements in a frequency range from $500 \mathrm{kHz}$ to $10 \mathrm{mHz}$ of $\mathrm{CB}$ electrodes were obtained before (stored) and after stepwise charge to $4.9 \mathrm{~V}$. All measurements were performed at OCV after the cell had reached steady state defined by a change $<5 \mathrm{mV} / \mathrm{h}$. The impedance results were modeled using the equivalent circuit presented in Figure 1. The $\mathrm{R}_{\mathrm{E}}-\mathrm{R}_{\mathrm{Al}} \mathrm{C}_{\mathrm{Al}}$ elements model the high-frequency region where $\mathrm{R}$ corresponds to a resistance and $\mathrm{C}$ corresponds to a capacitor. These values have been normalized to the geometrical surface area of the electrode $\left(0.785 \mathrm{~cm}^{2}\right)$. The low-frequency region has been modeled with a simplified transmission line (TL) for a porous electrode, according to De Levie model. ${ }^{24,25}$ This model involves a cylindrical pore with lenght $L$ and radius $r$, filled with the electrolytic solution, and the electronic resistance of the electrode is assumed to be much lower than the ionic resistance of the solution $\left(\mathrm{R}_{\mathrm{E}} \ll \mathrm{R}_{\text {ion }}\right)$. In case of a non-faradaic process, the overall impedance inside the pore is equal to:

$$
Z=\sqrt{\frac{R_{i o n, L}}{j \omega C_{d l, A} 2 \pi r}} \operatorname{coth} \sqrt{R_{i o n, L} * j \omega C_{d l, A} 2 \pi r}
$$

where $\mathrm{R}_{\text {ion, } \mathrm{L}}$ is the ionic resistance of the electrolyte per unit pore length $\left(\Omega \mathrm{cm}^{-1}\right)$ and $\mathrm{C}_{\mathrm{dl}, \mathrm{A}}$ is the electrical double layer capacitance per unit surface area $\left(\mathrm{Fcm}^{-2}\right)$. From this model we calculated the total double layer capacitance of the $\mathrm{CB}$ electrode $\mathrm{C}_{\mathrm{dl}}(\mathrm{F})$. The uniform transmission line for a flooded ideally polarized porous electrode can be seen in Figure 1. This model makes a good fit of the high- and low-frequency regions of the experimental data, but shows a small deviation in the mid-frequency part. Despite this, the model has been chosen as it provides an acceptable fit with a meaningful physical interpretation to the interface between $\mathrm{CB}$ surface and electrolyte in the extended porous network. The double layer capacitance is related to the total surface area $A$ :

$$
C_{d l}=\varepsilon \varepsilon_{0} \frac{A}{l}
$$

where $\varepsilon_{0}$ is the electric constant, and $\varepsilon$ and $l$ is the dielectric constant and the thickness of a surface layer, respectively. After cycling, Liion cells were transferred to MAX-IV Laboratory where they were dismantled in an Ar-filled glove box $\left(\mathrm{H}_{2} \mathrm{O}<1 \mathrm{ppm}\right)$. The carbon electrodes were washed with several drops of dimethyl carbonate (DMC). This washing is necessary to remove remaining electrolyte species in order to obtain spectra from the surface of the samples. The samples were mounted in a specially designed transfer chamber and transported to the analyzing chamber without exposure to the atmosphere. The measurements were performed using synchrotron radiation (beamline I-411) at the MAX IV Laboratory. Photons were monochromatized by a Zeiss SX-700 planar grating monochromator. Core level spectra of carbon (C 1s) spectra were measured using two different photon energies of $430 \mathrm{eV}$ and $835 \mathrm{eV}$ to obtain depth profile analysis of surface layer on carbon cathodes. Core level spectra of fluorine (F 1s) spectra were measured using photon energies of $835 \mathrm{eV}$. The spectra were energy calibrated using the hydrocarbon peak at $285.0 \mathrm{eV}$. The spectra were intensity normalized to 1 . Curve fitting was performed using IGOR Pro, and a linear background was subtracted before the spectra were deconvoluted. TEM imaging and selected area electron diffraction (SAED) of CB was carried out by using a JEOL $3000 \mathrm{~F}$ equipped with a $300 \mathrm{kV}$ FEG. EDS was carried out for compositional analysis by using an Oxford Instruments detector with an ultra-thin window. The analysis was performed using the Inca software. After opening the cells, the samples were washed by DMC to remove the electrolyte. All specimens were prepared for TEM by scratching electrode powders from the Al current collector and the powder was dispersed dryly onto Au TEM grids with a lacey carbon film. Particle sizes were analyzed from bright field TEM images using ImageJ software. To compare the intensities in the SAED data, the patterns were circularly integrated and the all intensities were normalized to the intensity of the first diffraction ring. XRD analyses was performed using a Bruker D8 TwinTwin X-ray diffractometer operating at $40 \mathrm{kV}$ and $40 \mathrm{~mA}$ using $\mathrm{Cu} \mathrm{K} \alpha$ radiation $(\lambda=1.5406 \AA)$.

\section{Results and Discussion}

Figure 2 a shows the first charge curves of Li-ion cells assembled using CB cathodes with $\mathrm{LiPF}_{6}$ or $\mathrm{LiClO}_{4}$ as the electrolyte salts. It can be seen that the $\mathrm{LiClO}_{4}$-based cell reached the anodic limit of $4.9 \mathrm{~V}$ much faster than the $\mathrm{LiPF}_{6}$-based cell. In other words, the $\mathrm{LiClO}_{4}$ based cell provided a smaller charge capacity, about $50 \mathrm{mAh} \cdot \mathrm{g}^{-1}$, while the $\mathrm{LiPF}_{6}$ cell yielded a larger charge capacity of about $800 \mathrm{mAh} \cdot \mathrm{g}^{-1}$. These capacities are comparable (considering differences in applied current densities) to previously reported results for Super P carbon black and noticeably smaller than capacities of similar cells with graphitic carbons or high surface area carbons like Ketjen black which provides irreversible charge capacity above $2000 \mathrm{mAh} \cdot \mathrm{g}^{-1} \cdot{ }^{12,13}$

To investigate the reversibility of these capacities, the cells were discharged to $2.5 \mathrm{~V}$ and then cycled 10 times between 4.9 and $2.5 \mathrm{~V}$. Figure $2 \mathrm{~b}$ shows that the charge capacities were significantly higher than the discharge capacities indicating irreversible electrochemical processes during charge. In addition, the charge capacity decreased significantly from the first cycle to the following cycles (note that the capacities are presented on a logarithmic scale). The small discharge capacity is the same in all cycles indicating that a minor reversible reaction occurs on the $\mathrm{CB}$ cathodes. This reversible capacity is due to the sum of the accumulated surface capacitance and the charge transfer from any reversible electrochemical processes. The latter could be intercalation/deintercalation of $\mathrm{PF}_{6}{ }^{-}$or $\mathrm{ClO}_{4}{ }^{-}$anions to/from the positive electrode, as this can provide a small reversible capacity. ${ }^{8,15-19}$

The large irreversible capacity (defined as the difference between the charge and the discharge capacity) can be explained by i) formation of a $\mathrm{AlF}_{3}$ passivation layer on the aluminum current collector via decomposition of $\mathrm{LiPF}_{6,},{ }^{26,27}$ and ii) reactions between the electrolyte and the surface functional groups on the carbon surface. In order to clarify the contribution of $\mathrm{Al}$ current collector corrosion to the total irreversible capacities observed for $\mathrm{CB}$ cathodes, identical cells were assembled using only an $\mathrm{Al}$ disk (as it is without any carbon black or active material on it) as cathode. Figure $2 \mathrm{c}$ shows that the irreversible 

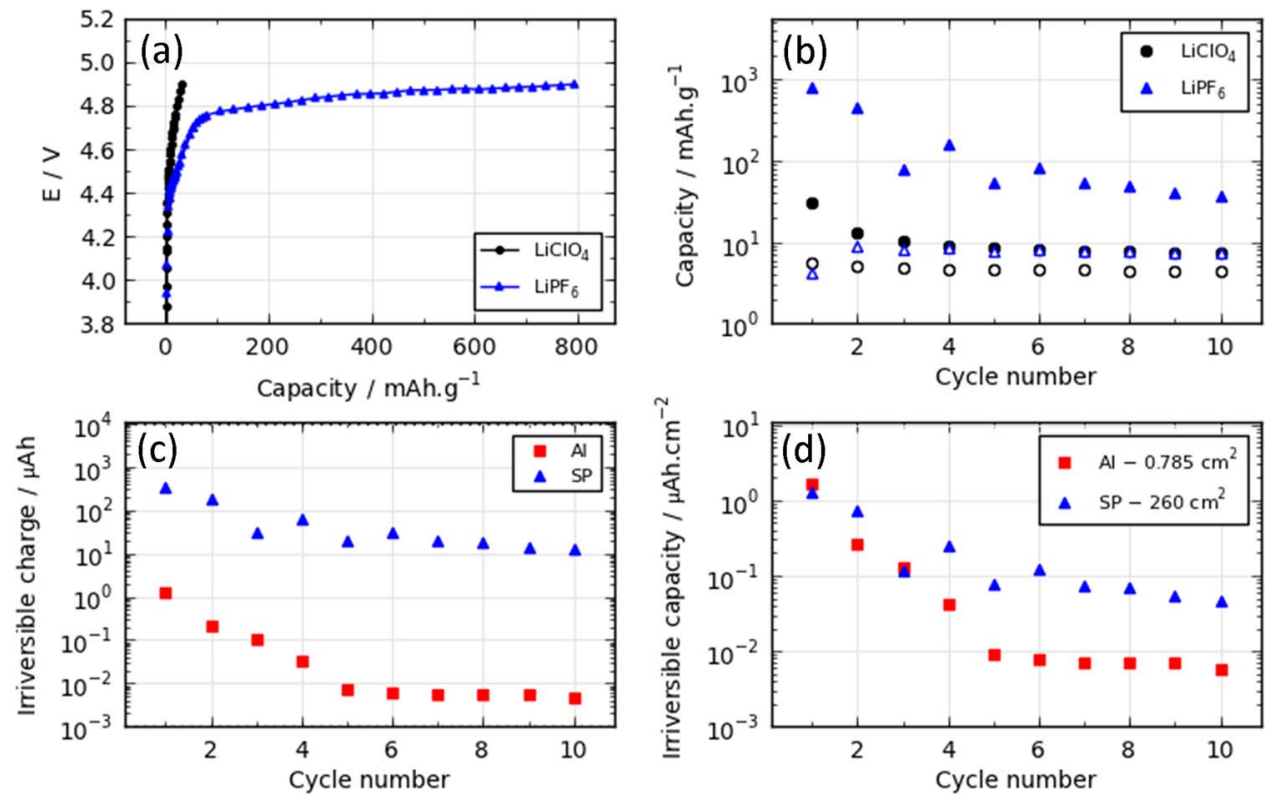

Figure 2. (a) First charge curves of $\mathrm{Li}$-ion cells using $\mathrm{CB}$ cathode with $\mathrm{LiPF}_{6}$ or $\mathrm{LiClO}_{4}$ as electrolyte salt dissolved in $\mathrm{EC}$ :DEC (1:1) solvent. (b) Charge/discharge capacities for the first 10 cycles of $\mathrm{CB}$ cathode cycled between 4.9-2.5 V using the same electrolytes. Solid points are for charge while open points are for discharge capacities. (c) Logarithmic irreversible capacity vs. cycle number for a CB electrode and a bare Al electrode using LiPF 6 salt. (d) Same as (c), but divided by surface area of the electrodes.

charge $\left(\mathrm{Q}_{\text {irr }}\right)$ is order of magnitudes higher in the $\mathrm{CB}$ electrode than in an $\mathrm{Al}$ electrode in cells with $\mathrm{LiPF}_{6}$ electrolyte salt, showing that the $\mathrm{Al}$ current collector corrosion is not the main origin of $\mathrm{Q}_{\mathrm{irr}}$. However, one may argue that the higher surface area of carbon particles causes the higher degree of $Q_{\text {irr }}$ in the CB electrode. Figure $2 d$ shows $Q_{\text {irr }}$ per surface area of the electrodes. The surface area for the Al disk is estimated to be $0.785 \mathrm{~cm}^{2}$, assuming a smooth surface. In case of $\mathrm{CB}$ electrodes, the surface area is estimated by using a BET value of $62 \mathrm{~m}^{2} \cdot \mathrm{g}^{-1}$ for CB powder, assuming that all particles are available for charge accumulation i.e. no surface blocking due to binder etc. Thus, the total surface area of $\mathrm{CB}$ electrode is assumed to be equal to $260 \mathrm{~cm}^{2}$. Figure $2 \mathrm{~d}$ shows that $\mathrm{Q}_{\mathrm{irr}} / \mathrm{cm}^{2}$ of $\mathrm{Al}$ disk is significantly deceased after few cycles, which is known to be due to formation of a passivation layer of $\mathrm{AlF}_{3}$. However, $\mathrm{Q}_{\mathrm{irr}} / \mathrm{cm}^{2}$ of $\mathrm{CB}$ electrode is still about one order of magnitude higher for $\mathrm{CB}$ in the following cycles. This finding confirms that $\mathrm{Q}_{\text {irr }}$ in long term cycling is originated from $\mathrm{CB}$ particles. Winter et al. have shown that the nature and properties of CBs such as presence of functional groups and graphitic structure influence irreversible capacities at high voltage. ${ }^{16-18}$ They have shown that thermal treatment of $\mathrm{CB}$ results in graphitization of $\mathrm{CB}$ as well as removal of functional groups, which consequently can decrease $\mathrm{Q}_{\mathrm{irr}}$ of CB.

To investigate a possible formation of electrolyte decomposition species in or on $\mathrm{CB}$ particles at high voltages, $\mathrm{CB}$ electrodes were analyzed using synchrotron-based SOXPES. Figure 3a shows C1s spectra of a CB cathode cycled 10 times between 4.9-2.5 V using $\mathrm{LiPF}_{6}$ as the electrolyte salts. Also, $\mathrm{C} 1 \mathrm{~s}$ spectra of a $\mathrm{CB}$ cathode that was cycled between $4.3-2.5 \mathrm{~V}$, as well as, C1s spectra of pristine and stored $\mathrm{CB}$ electrodes are presented in the Figure $3 \mathrm{a}$. The $\mathrm{C} 1 \mathrm{~s}$ spectrum of the pristine sample contains 4 main contributions at the binding energies of $284.6 \mathrm{eV}, 285 \mathrm{eV}, 286.5 \mathrm{eV}$, and $290.9 \mathrm{eV}$ assigned to Super P, hydrocarbons, $\mathrm{CH}_{2}$ (from binder), and $\mathrm{CF}_{2}$ (from binder), respectively. ${ }^{28,29}$ There are also two small contributions at binding energies of $288.7 \mathrm{eV}$ and $293.5 \mathrm{eV}$ representing $\mathrm{CF}$ and $\mathrm{CF}_{3}$, respectively, in Kynar binder. ${ }^{28-30}$ Interestingly, the $\mathrm{C} 1 \mathrm{~s}$ spectrum of the stored sample shows different features compared to the spectrum of the pristine sample, as the stored sample has a higher intensity/contribution of the hydrocarbon peak (red peak at $285 \mathrm{eV}$ ). Also, the intensity of the peak at $286.5 \mathrm{eV}$ (green peak) is increased, which indicates presence of $\mathrm{C}-\mathrm{O}$ bond in the surface region of the stored CB particles. In addition, a small peak has appeared at $287.5 \mathrm{eV}$ originating from $\mathrm{O}-\mathrm{C}-\mathrm{O}$ and/or $\mathrm{C}=\mathrm{O}$ bonds. ${ }^{28-30}$ The changes in the spectrum of the stored sample compared to the pristine sample shows that the electrolyte solution partially decomposes in/at the surface of $\mathrm{CB}$ particles when the electrode is immersed in the electrolyte. It should be mentioned again that all the electrodes were washed with DMC before SOXPES measurements to make sure no electrolyte remained on the surface of electrodes. Similar, but not identical, results regarding the surface degradation on stored carbon electrodes have been observed in other studies using FTIR..$^{11,14}$ Demeaux et al. ${ }^{11}$ proposed that polyether and polycarbonate species form on the surface of CB samples stored for longer time (4 weeks) at higher temperature $\left(40^{\circ} \mathrm{C}\right)$. While our SOXPES confirms formation of ether-based species, we did not observe formation of carbonate-based compound on the stored samples. Also, Demeaux et al. ${ }^{11}$ suggested a formation of a surface layer based on scanning electron microscopy (SEM). However, Syzdek et al. did not detect any surface layer in SEM results, and this was explained by the possibly removal of any surface layer by DMC prior to imaging. ${ }^{14}$ The formation of decomposition species in the stored sample may take place by a redox reaction as the cells have open circuit voltage about $3 \mathrm{~V}$ vs. $\mathrm{Li} / \mathrm{Li}^{+} .{ }^{11}$ Compared to well-studied storage degradation of cathode materials, ${ }^{31-34}$ less attention has been paid to spontaneous reaction occurring in the surface region of stored $\mathrm{CB}$. Thus, the presented results are useful for detecting the origin of surface layer on stored cathodes, because decomposition products originated from active materials and carbon black may overlap with each other. ${ }^{11}$

Surprisingly, the $\mathrm{C} 1 \mathrm{~s}$ spectrum of the $\mathrm{CB}$ cathode cycled 10 times up to $4.3 \mathrm{~V}$ present similar features to the $\mathrm{C} 1 \mathrm{~s}$ spectrum of pristine sample indicating that no major decomposition product is present in the $\mathrm{CB}$ cathode when cycled up to $4.3 \mathrm{~V}$. The $\mathrm{C} 1 \mathrm{~s}$ spectrum consists of extra minor contribution from $\mathrm{O}-\mathrm{C}-\mathrm{O}$ and/or $\mathrm{C}=\mathrm{O}$ bonds compared to the pristine sample. The results could suggest that the decomposition species in the surface of the stored $\mathrm{CB}$ diminishes when the $\mathrm{CB}$ cathode is cycled up to $4.3 \mathrm{~V}$. This can, for example, occur by oxidation and/or dissolution/desorption. ${ }^{30,35}$

Cycling the CB cathode between 4.9-2.5 V using $\mathrm{LiPF}_{6}$ electrolyte, we could detect an increase in the relative intensity of peaks at $287.5 \mathrm{eV}$ and $290.9 \mathrm{eV}$. The former originates from O-C-O and/or $\mathrm{C}=\mathrm{O}$ bonds while the latter from carbonate species $\left(\mathrm{CO}_{3}\right){ }^{28-30}$ The 

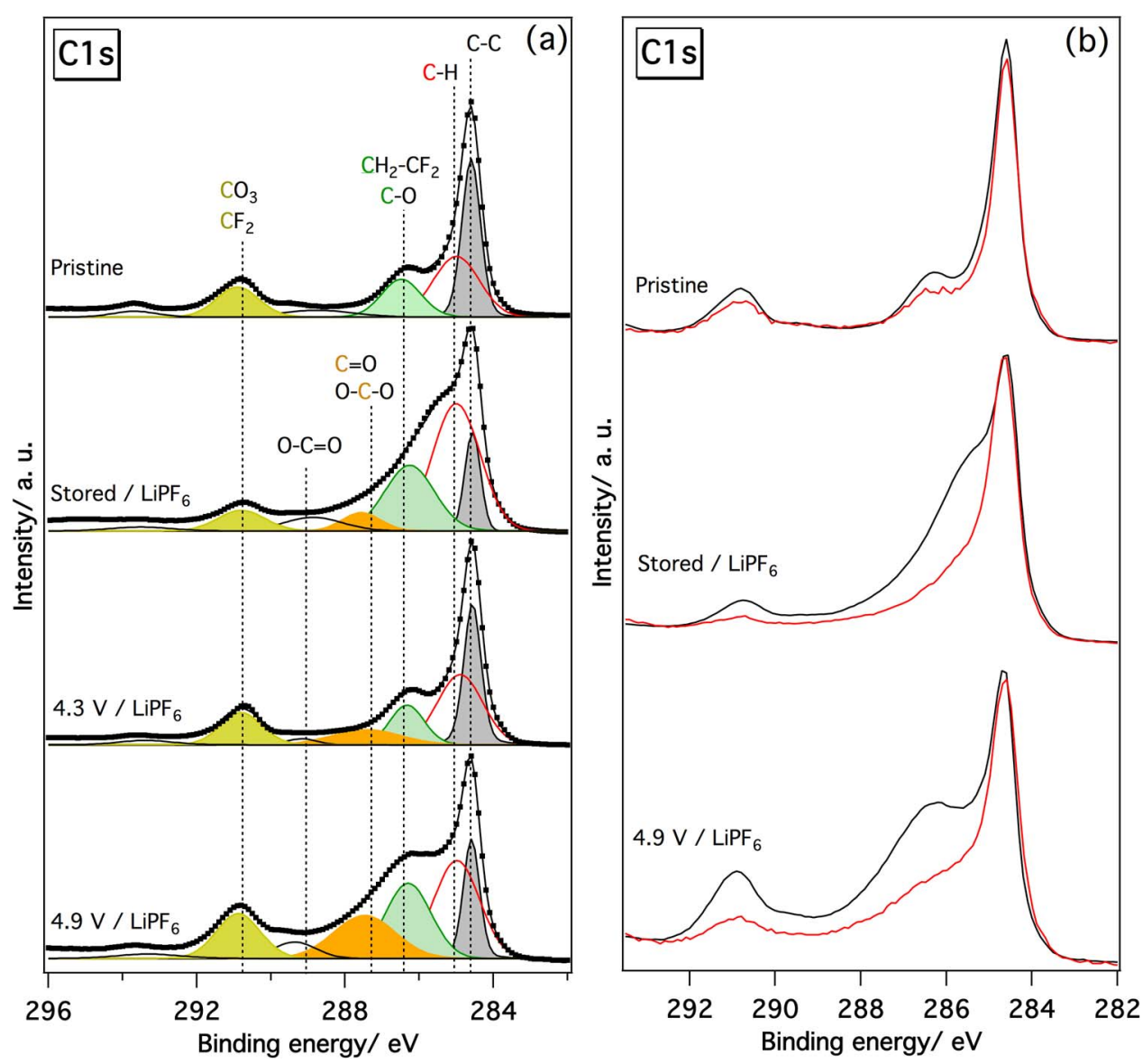

Figure 3. (a) Deconvoluted C1s spectra of pristine, stored, and cycled CB cathodes using $\mathrm{LiPF}_{6}$ in EC:DEC electrolyte. The spectra were measured by photon energy of $430 \mathrm{eV}$. (b) $\mathrm{C} 1 \mathrm{~s}$ spectra of the same samples measured using two photon energies of $430 \mathrm{eV}$ (black) and $835 \mathrm{eV}$ (red).

increase in the relative intensity of these peaks implies that the $\mathrm{CB}$ cathode decompose EC:DEC solvent partially when the cell was cycled to $4.9 \mathrm{~V}$.

To obtain a depth profiling of the surface layer, the CB cathodes were analyzed using two different photon energies of $430 \mathrm{eV}$ and $835 \mathrm{eV}$, as presented by the black and red spectra, respectively, in Figure $3 \mathrm{~b}$. For the pristine $\mathrm{CB}$ electrode, the $\mathrm{C} 1 \mathrm{~s}$ spectra look similar using these two photon energies, as expected. A minor difference is that the $\mathrm{C} 1 \mathrm{~s}$ spectrum measured with lower photon energy shows slightly more contribution from binder (peaks at $286.5 \mathrm{eV}$, and $290.9 \mathrm{eV}$ ), indicating that concentration of binder is slightly higher on top surface. The stored and cycled samples display that the $\mathrm{C} 1 \mathrm{~s}$ spectra are more similar to the pristine sample for the higher photon energy of $835 \mathrm{eV}$. The spectra obtained with the higher photon energy are originated from increased depth of about $5-7 \mathrm{~nm} .{ }^{36}$ Therefore, the highest concentration of electrolyte decomposition species are found in a thin, about $1-3 \mathrm{~nm}$, surface region of the CB.

Figure 4a shows $\mathrm{C} 1 \mathrm{~s}$ spectra of $\mathrm{CB}$ electrodes stored and cycled to $4.9 \mathrm{~V}$ using $\mathrm{LiClO}_{4}$ in EC:DEC electrolyte. Both spectra demonstrate presence of decomposed electrolyte species on the surface of the sample. However, compared to the $\mathrm{LiPF}_{6}$-based samples, the spectra of $\mathrm{LiClO}_{4}$-based sample show a less degree of difference from the spectrum the pristine sample. Also, the spectra of $\mathrm{LiClO}_{4}$-based samples measured by two photon energies of $430 \mathrm{eV}$ and $835 \mathrm{eV}$ (black and red spectra respectively in Figure $4 \mathrm{~b}$ ) are more similar than those for $\mathrm{LiPF}_{6}$-based samples (Figure $3 \mathrm{~b}$ ). This means that a smaller amount of degradation products are formed in the surface of $\mathrm{CB}$ cathodes in $\mathrm{LiClO}_{4}$-based cells compared to the $\mathrm{LiPF}_{6}$-based cells. This is in agreement with the capacity results presented in Figure 2, which indicated that charge capacity of $\mathrm{LiClO}_{4}$-based cells is smaller than that of $\mathrm{LiPF}_{6}$-based cells.
The F1s spectra of all the samples look more or less similar since the peak in the spectra are substantially originated from binder of electrodes (Figure 5). The peak at $688 \mathrm{eV}$ mainly represent bond between $\mathrm{F}$ and $\mathrm{C}$ in the Kynar binder. However, a closer look at the spectra reveals that a small shoulder is present at $685 \mathrm{eV}$ in the spectra of stored and cycled samples when $\mathrm{LiPF}_{6}$ was used as the electrolyte salt. This small contribution represents $\mathrm{LiF}$ formed due to partial decomposition of $\mathrm{LiPF}_{6},{ }^{30}$ suggesting that decomposed $\mathrm{LiPF}_{6}$ salt is found in the surface region of the $\mathrm{CB}$.

As described in detail above decomposed electrolyte species are found in the surface region of the $\mathrm{CB}$ particle according to the SOXPES results. The structure of these decomposed electrolyte species is, however, not clear from the SOXPES results. It could for example be speculated that the species are present as layers partly covering the $\mathrm{CB}$ surfaces, or alternatively that the species are integrated into the $\mathrm{CB}$ top surface layer. To address this question, high-resolution TEM (HRTEM) was applied and HRTEM images of the pristine and charged $\mathrm{CB}$ electrodes are shown in Figure 6. From these images no surface layers on the $\mathrm{CB}$ particles can be observed in any of the samples. However, the internal structure of the pristine $\mathrm{CB}$ particles indicates the presence of graphitic structures approximately in the direction along the surface of the primary $\mathrm{CB}$ particles, while this structure is less pronounced for the charged sample (HRTEM image of the stored sample is presented in Figure S1 displaying slightly changes between pristine and stored $\mathrm{CB}$ particles). These results could indicate a loss in crystallinity after storing and charging. Also, for the charged sample the surface of particle became less sharp and in many areas the damaged graphitic was observed. EDS analysis showed that phosphorus and fluorine signals increase from stored to charged samples, suggesting that more $\mathrm{PF}_{6}^{-}$originated compounds are present in the charged sample (see Figure 7). These results together with the 

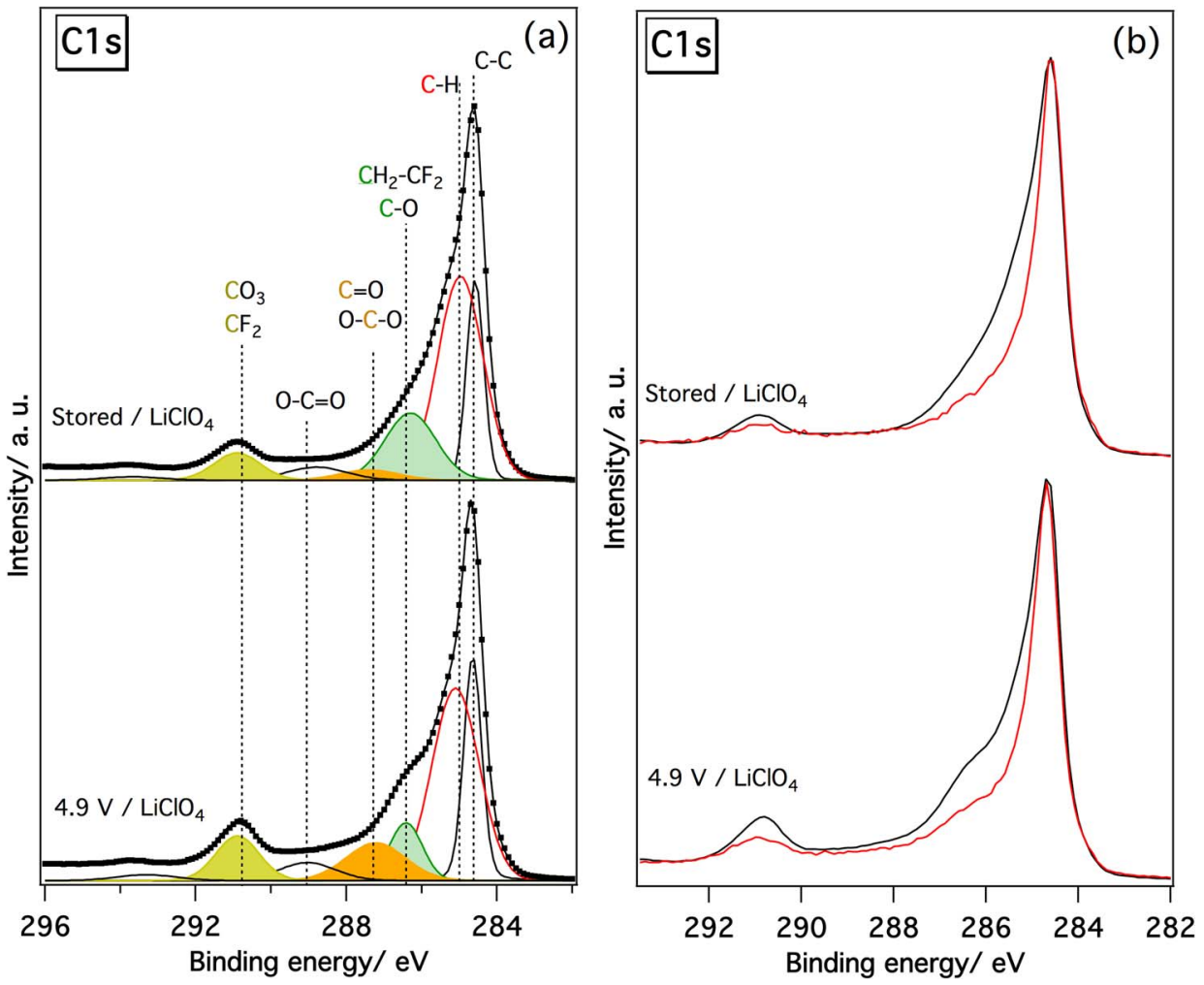

Figure 4. (a) Deconvoluted C1s spectra of stored and cycled $\mathrm{CB}$ cathodes using $\mathrm{LiClO}_{4}$ in EC:DEC electrolyte. The spectra were measured by photon energy of $430 \mathrm{eV}$. (b) C1s spectra of the same samples measured using two photon energies of: $430 \mathrm{eV}$ (black) and $835 \mathrm{eV}$ (red).

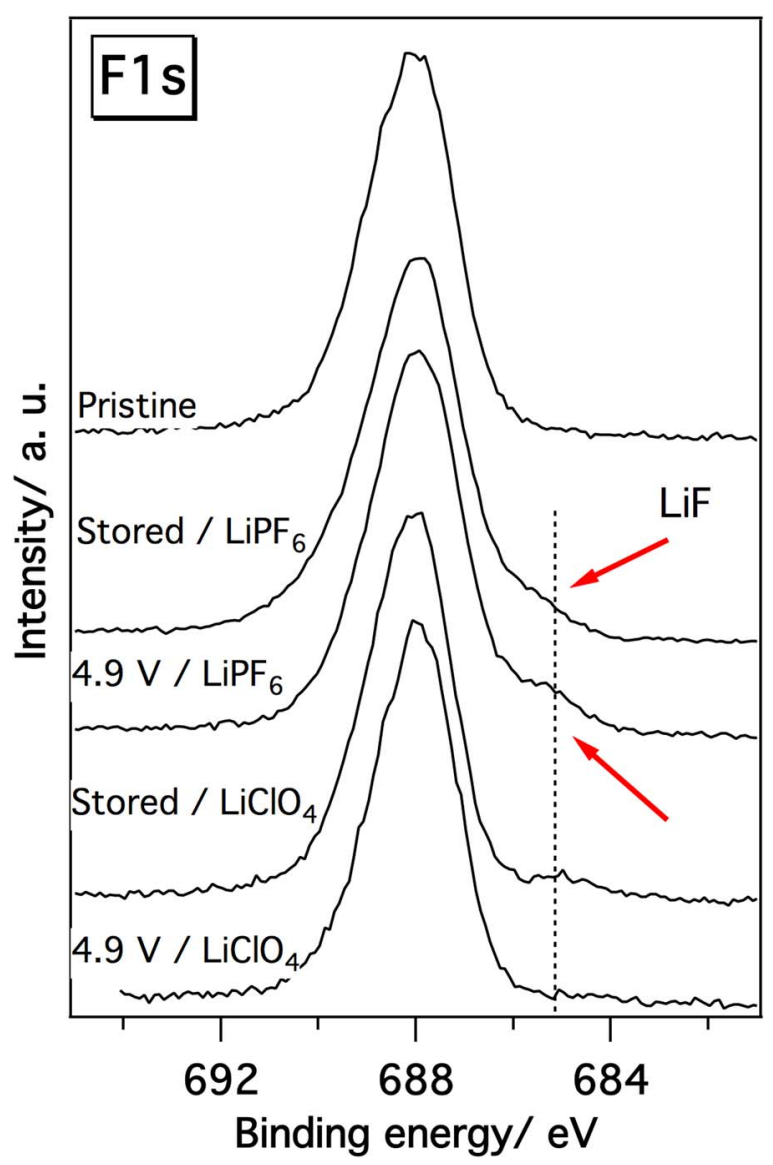

Figure 5. F1s spectra of pristine, stored, and cycled CB cathodes using $\mathrm{LiPF}_{6}$ and $\mathrm{LiClO}_{4}$ as the electrolyte salt.
SOXPES shows that the decomposed electrolyte species are present, not as layers partly covering the $\mathrm{CB}$ particles, but integrated into the surface of the CB. To evaluate the possible loss of crystallinity indicated from the HRTEM images, SAED data for all three electrodes are presented in Figure 8 along with normalized circular integration of the SAED patterns. Three main peaks can be distinguished in the pristine electrode corresponding to the $(002),(100)$ and (110) reflections indicating that a partially graphitic structure exists in SP, which is in agreement with XRD results presented in Figure S2. The broad peaks are indicative of low-graphitized $\mathrm{CB}$ with short-range crystalline domains. ${ }^{17}$ Figure 8 shows that storing and charging $\mathrm{CB}$ leads to broadening of the diffraction peaks which indicates a loss in crystallinity, consistent with the HRTEM images. The distance between the sheets in the graphitic domains, which is obtained by the position of the $\mathrm{d}_{002}$ reflection, is determined to $3.3 \pm 0.1 \AA$ for the pristine electrode. This value is slightly increased to $3.5 \pm 0.1 \AA$ for the charged electrodes. This increase is much smaller than the increase expected for complete intercalation of $\mathrm{PF}_{6}{ }^{-}$anions into the graphitic domain (i.e. $4.5 \AA$ ).${ }^{19}$ Finally, TEM images were recorded at lower magnification to evaluate the overall structure of the three samples. This analysis showed that the mean particle sizes slightly changed (see Figure 9). In the pristine electrode, the mean particle size is $33.2 \pm 1.2 \mathrm{~nm}$, in the stored electrode it is $35.3 \pm 1.0 \mathrm{~nm}$ and after cycling (at the charged stat) the value has increased to $40.2 \pm 1.6 \mathrm{~nm}$. The loss of crystallinity and particle swelling of the stored and charged CB samples could possibly be explained partly by absorption of electrolyte solution followed by structural rearrangement of the internal $\mathrm{CB}$ structure. Also, the integration of decomposed electrolyte species to $\mathrm{CB}$ particles could influence $\mathrm{CB}$ particles.

The impedance result of a stored CB electrode is presented in Figures 10a and 10b. The Nyquist plot consists of a large semicircle in the high frequency range (between $10 \mathrm{kHz}$ and $10 \mathrm{~Hz}$ ) and an almost vertical tail in the low frequency range. The high frequency side of the semicircle intersects with the $\mathrm{x}$-axis at $5 \Omega \mathrm{cm}^{2}\left(\mathrm{R}_{\mathrm{E}}\right)$. This value originates mainly from the ionic resistance of the electrolyte between 

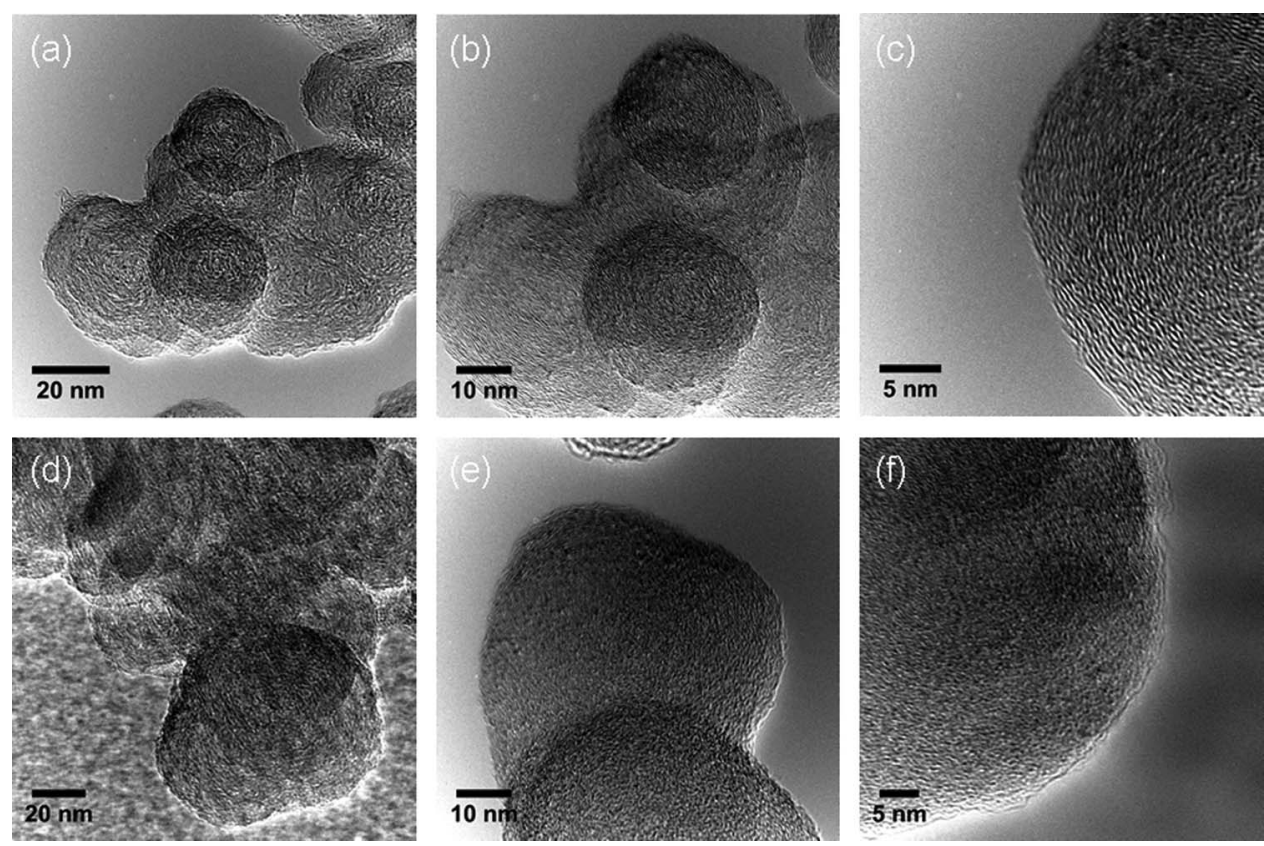

Figure 6. HRTEM images of CB samples: (a-c) pristine and (d-f) charged.

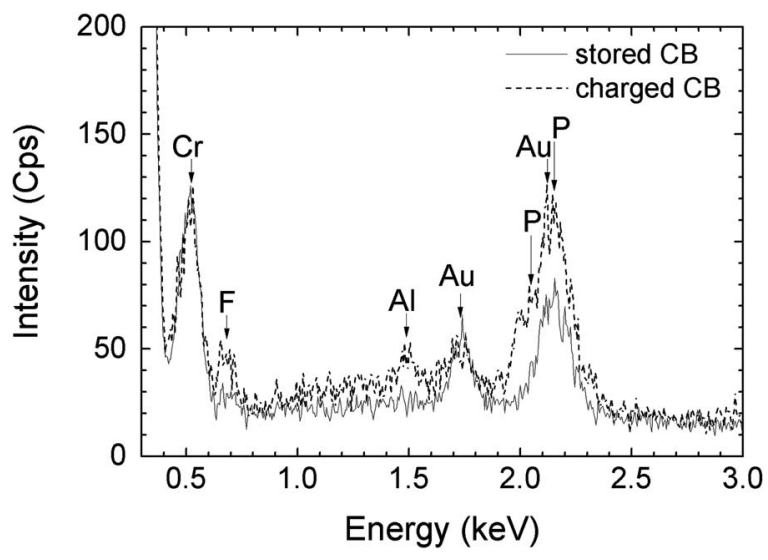

Figure 7. Normalized EDS spectra of stored (solid) and charged (dash) electrodes. A larger content of $\mathrm{F}$ and $\mathrm{P}$ was found in the charged electrode. Al originates from the preparation step when $\mathrm{CB}$ was scratched from the $\mathrm{Al}$ current collector. $\mathrm{Cr}$ and $\mathrm{Au}$ originate from the TEM grid.
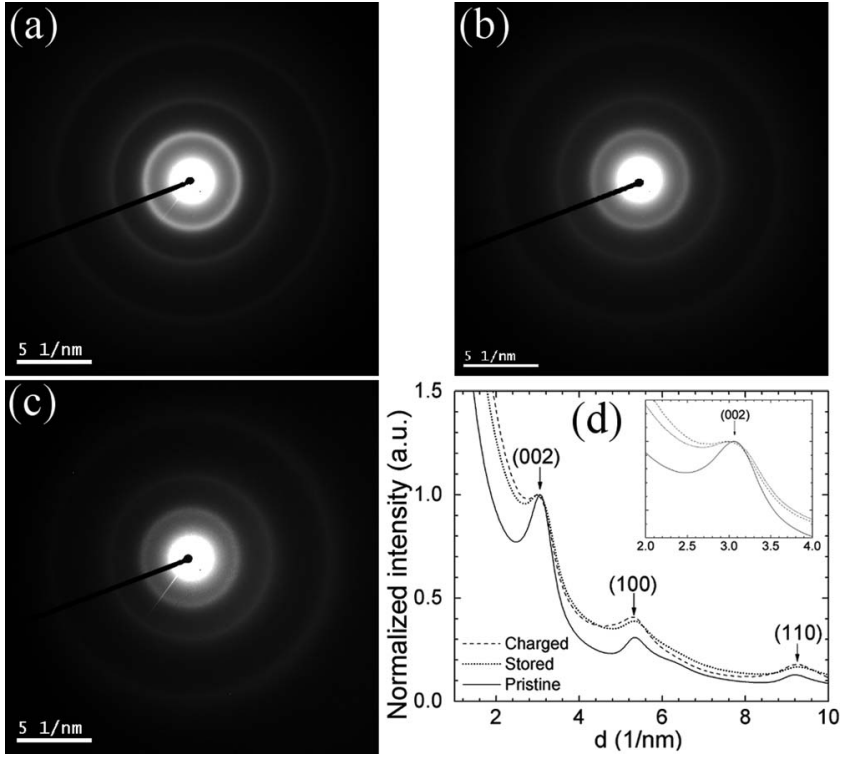

Figure 8. SAED patterns of (a) pristine, (b) stored, and (c) charged CB samples. Corresponding intensity profiles from the SAED patterns are shown in frame (d). The intensities are normalized to the intensity of the first diffraction ring (002). Inset of frame (d) shows a zoom-in of the first diffraction peak.
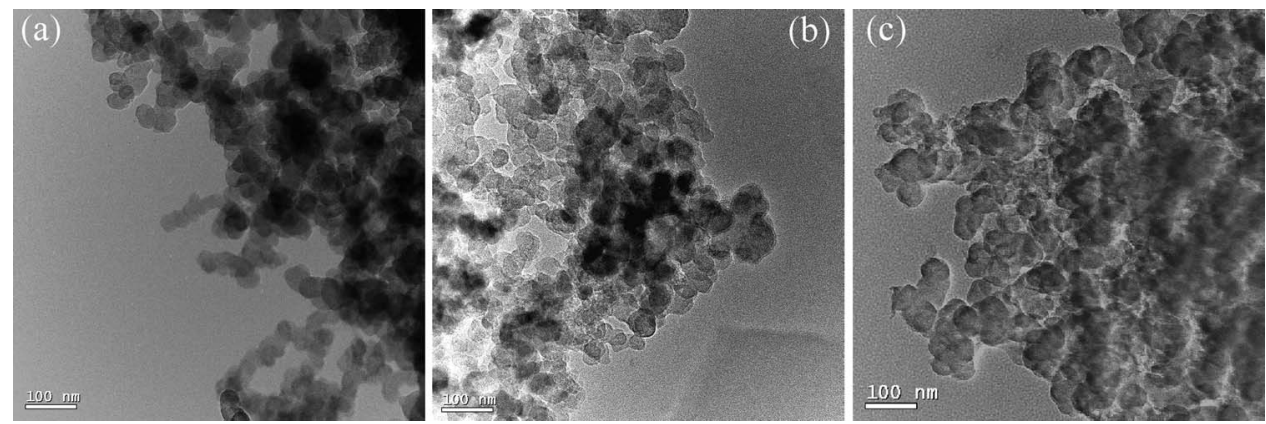

Figure 9. TEM images of (a) pristine, (b) stored, and (c) charged CB electrodes. 

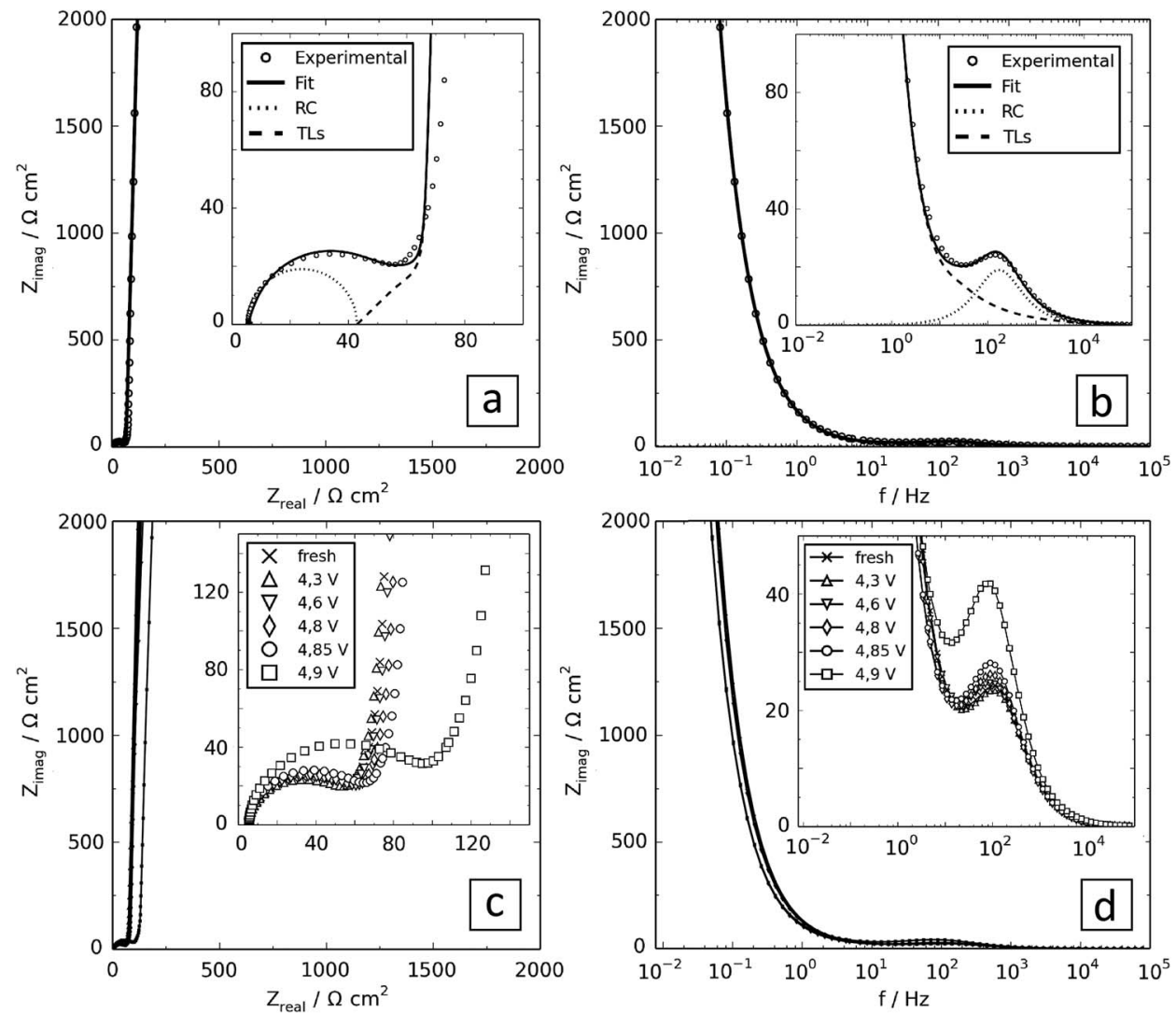

Figure 10. (a) Nyquist and (b) Bode plots of a stored $\mathrm{CB}$ electrode including fit using the equivalent circuit in equation 1. (c) Nyquist and (d) Bode plots of a CB cathode before, during and after stepwise charge to $4.9 \mathrm{~V}$. The EIS measurements are performed at OCV after relaxation. All insets show a zoomed view of the high frequency region.

the cathode and the Li reference electrode. The semicircle $\left(\mathrm{R}_{\mathrm{Al}} \mathrm{C}_{\mathrm{Al}}\right)$ can be assigned to the interface between the aluminum current collector and the porous carbon network. ${ }^{37}$ The low-frequency part (TLs) of the Nyquist plot shows a long capacitive tail, which refers to the double layer capacitance of the ion-blocking $\mathrm{CB}$ surface in the porous electrodes. ${ }^{25}$ Since the measurements are obtained at OCV no charge transfer reaction is expected. The Bode plot in Figure 10b shows the frequency domain of the impedance response. The impedance response from a $\mathrm{CB}$ electrode before, during, and after stepwise charge to $4.9 \mathrm{~V}$ is shown in Figure 10c. All measurements were performed at OCV after the cell had reached steady state. An increase in the semicircle and a small change in the angle of the tail are observed. Fitting of each plot was performed and the values for $\mathrm{R}_{\mathrm{Al}}, \mathrm{C}_{\mathrm{Al}}, \mathrm{R}_{\mathrm{ion}, \mathrm{L}}$ and $\mathrm{C}_{\mathrm{dl}}$ are extracted and shown as a function of the charge potential in Figure 11. The $\mathrm{Al} / \mathrm{CB}$ interface resistance $\left(\mathrm{R}_{\mathrm{Al}}\right)$ remains constant up to $4.3 \mathrm{~V}$ after which it increases slowly until $4.85 \mathrm{~V}$ and suddenly increases significantly at $4.9 \mathrm{~V}$. The capacitance of the $\mathrm{Al} / \mathrm{CB}$ interface $\left(\mathrm{C}_{\mathrm{Al}}\right)$ is almost constant until $4.8 \mathrm{~V}$ after which it suddenly decreases. The increase in $\mathrm{R}_{\mathrm{Al}}$ (Figure 11a) could be explained by the growing of resistive surface layers between aluminum and carbon particles. From $4.0 \mathrm{~V}$ and above an $\mathrm{AlF}_{3}$ surface layer will form on aluminum which fits with the increase in the slope above $4.3 \mathrm{~V}^{26,27} \mathrm{~A}$ decrease in $\mathrm{C}_{\mathrm{Al}}$
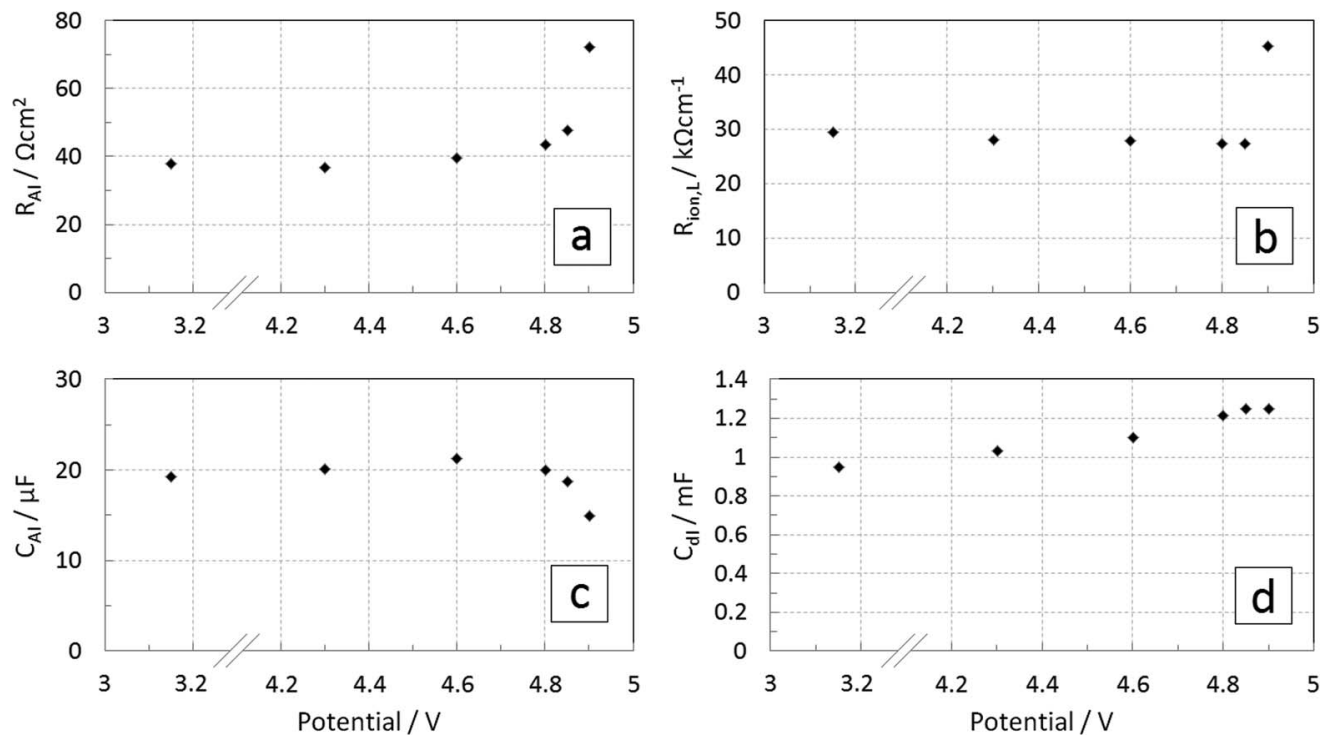

Figure 11. (a) $A l / C B$ interface resistance $R_{A l}$, (b) Electrolyte resistance per unit pore length $R_{\text {ion, }, \mathrm{L}}$, (c) $A l / C B$ interface capacitance $C_{A l}$ and d) $C B$ double layer capacitance $\mathrm{C}_{\mathrm{dl}}$ as function of charging voltage. 
(Figure 11c) after $4.8 \mathrm{~V}$ supports that an interphase layer is formed. A formation of an $\mathrm{AlF}_{3}$ layer will lead to an increase of the thickness of double layer and to a reduction of dielectric constant $\varepsilon$ (EC and DEC have $\varepsilon$ equal to 89.6 and 3.12 respectively, while $\mathrm{AlF}_{3}$ has a $\varepsilon$ equal to $2.2^{38}$ ). According to equation 2 these factors will both lead to a reduction of $\mathrm{C}_{\mathrm{Al}}$. The ionic resistance of the electrolyte in the pores $\left(\mathrm{R}_{\mathrm{ion}, \mathrm{L}}\right)$ is almost constant until $4.85 \mathrm{~V}$ after which it suddenly increases at $4.9 \mathrm{~V}$. This increase is possibly linked to a change in the pore structure induced by the particle growth. Finally, the carbon surface double layer capacitance $\left(\mathrm{C}_{\mathrm{dl}}\right)$ increases steadily from 0.95 to $1.25 \mathrm{mF}$ at $4.85 \mathrm{~V}$ after which it keeps a constant value (Figure 11d). Normalization of the initial carbon double layer capacitance to the total surface area of the electrode $\left(260 \mathrm{~cm}^{2}\right)$, gives an $\mathrm{C}_{\mathrm{dl}, \mathrm{A}}$ equal to $3.6 \mu \mathrm{F} \mathrm{cm}^{-2}$. This value is close to the values found in literature i.e. 5 to $10 \mu \mathrm{Fcm}^{-2}$. ${ }^{39}$ The actual surface area is slightly smaller due to blocking with PVDF binder and isolated particles not connected to the conductive network, and this can explain the smaller value. According to equation 2 , the capacitance is directly correlated to a change in the surface area. As indicated from TEM analysis the CB particles swell from 35 to $40 \mathrm{~nm}$, increasing their surface area with $30 \%$. This is in agreement with the observed increase of $\mathrm{C}_{\mathrm{dl}}$ by assuming that the conductive network is intact. Alternatively, increased wetting of the electrode network could also explain such an increase in $\mathrm{C}_{\mathrm{dl}}$. Therefore, since no decrease in double layer capacitance was observed, the EIS result cannot prove the formation of a surface layer on top of the $\mathrm{CB}$ particles.

\section{Conclusions}

Synchrotron-based SOXPES results revealed that spontaneous decomposition of electrolyte solution $\left(\mathrm{LiPF}_{6}\right.$ dissolved in EC:DEC) occurs in the surface region of carbon black particles stored in the electrolyte in the absence of external potential and current. Consequently, mainly hydrocarbons and ether species $(\mathrm{C}-\mathrm{O})$ originated from EC:DEC, and also, $\mathrm{LiF}$ originated from $\mathrm{LiPF}_{6}$ decomposition are formed in the surface of the stored electrode. The decomposition species diminish when the electrode is cycled between $2.5-4.3 \mathrm{~V}$, which suggests that they were oxidized/desorbed when electrochemical processes started. Increased anodic potential to $4.9 \mathrm{~V}$ leads to irreversible charges, and thus, to an increase in the impedance of the carbon cathode and to formation of a quite different composition of degraded electrolyte species compared to that formed in the stored electrode. The electrolyte/cathode interphase formed at high voltages consists of relatively higher contribution from $\mathrm{O}-\mathrm{C}-\mathrm{O}$ and/or $\mathrm{C}=\mathrm{O}$ bonds as well as carbonates compounds $\left(\mathrm{CO}_{3}\right)$ originating from the solvent, in addition to hydrocarbons, ethers and LiF. Depth profile analysis of the interphase indicated that the concentration of the decomposed species is highest at the outermost CB surface (1-3 nm). TEM and EIS showed no distinctive surface layer indicating that the electrolyte degradation products are likely integrated into the surface region of the $\mathrm{CB}$. The findings suggest that cathode/electrolyte interphases commonly observed on high voltage cathodes may originate from reactions between carbon black and electrolyte and not necessarily between active material and electrolyte.

\section{Acknowledgments}

The authors gratefully acknowledge financial support from the Danish Strategic Research Council through the project "Advanced Lifetime Predictions of Battery Energy Storage" (contract no. 0603-
00589B). The EC FP7 project Hi-C (grant no. 608575) and Copenhagen Cleantech Cluster are also acknowledged for financial support. Kristian Bastholm Knudsen is acknowledged for help in the EIS analysis.

\section{References}

1. P. J. Hall and E. J. Bain, Energy Policy, 36, 4352 (2008)

2. R. Younesi, Front. Energy Res., 2,1 (2014).

3. D. Liu, W. Zhu, J. Trottier, C. Gagnon, F. Barray, A. Guerfi, A. Mauger, H. Groult, C. M. Julien, J. B. Goodenough, and K. Zaghib, RSC Adv., 4, 154 (2014).

4. A. Kraytsberg and Y. Ein-Eli, Adv. Energy Mater, 2, 922 (2012).

5. R. Younesi, S. Malmgren, K. Edström, and S. Tan, J. Solid State Electrochem., 18, 2157 (2014)

6. K. Xu, Chem. Rev., 114, 11503 (2014)

7. H. Duncan, N. Salem, and Y. Abu-Lebdeh, J. Electrochem. Soc., 160, A838 (2013).

8. A. Watanabe, K. Mori, H. Ishikawa, and Y. Nakamura, J. Electrochem. Soc., 134, 1318 (1987).

9. S. Mandal, J. M. Amarilla, J. Ibáñez, and J. M. Rojo, J. Electrochem. Soc., 148, A24 (2001).

10. L. Fransson, T. Eriksson, K. Edström, T. Gustafsson, and J. O. Thomas, J. Power Sources, 101, 1 (2001).

11. J. Demeaux, M. Caillon-Caravanier, H. Galiano, D. Lemordant, and B. Claude-Montigny, J. Electrochem. Soc., 159, A1880 (2012).

12. F. La Mantia, R. A. Huggins, and Y. Cui, J. Appl. Electrochem., 43, 1 (2012).

13. J. Zheng, J. Xiao, W. Xu, X. Chen, M. Gu, X. Li, and J.-G. Zhang, J. Power Sources, 227, 211 (2013)

14. J. Syzdek, M. Marcinek, and R. Kostecki, J. Power Sources, 245, 739 (2014).

15. W. Märkle, N. Tran, D. Goers, M. E. Spahr, and P. Novák, Carbon N. Y., 47, 2727 (2009).

16. X. Qi, B. Blizanac, A. DuPasquier, A. Lal, P. Niehoff, T. Placke, M. Oljaca, J. Li, and M. Winter, J. Electrochem. Soc., 162, A339 (2015).

17. X. Qi, B. Blizanac, A. DuPasquier, P. Meister, T. Placke, M. Oljaca, J. Lie, and M. Winter, Phys. Chem. Chem. Phys., 16, 25306 (2014).

18. T. Placke, G. Schmuelling, R. Kloepsch, P. Meister, O. Fromm, P. Hilbig, H.-W. Meyer, and M. Winter, Zeitschrift für Anorg. und Allg. Chemie, 640, 1996 (2014).

19. J. A. Seel and J. R. Dahn, J. Electrochem. Soc., 147, 892 (2000).

20. K. Edström, T. Gustafsson, and J. O. Thomas, Electrochim. Acta, 50, 397 (2004)

21. H. Duncan, Y. Abu-Lebdeh, and I. J. Davidson, J. Electrochem. Soc., 157, A528 (2010).

22. K. J. Carroll, M.-C. Yang, G. M. Veith, N. J. Dudney, and Y. S. Meng, Electrochem. Solid-State Lett., 15, A72 (2012).

23. A. S. Andersson, B. Kalska, L. Häggström, and J. O. Thomas, Solid State Ionics, 130, 41 (2000).

24. R. de Levie, Electrochim. Acta, 9, 1231 (1964).

25. N. Ogihara, S. Kawauchi, C. Okuda, Y. Itou, Y. Takeuchi, and Y. Ukyo, J. Electrochem. Soc., 159, A1034 (2012).

26. A. H. Whitehead and M. Schreiber, J. Electrochem. Soc., 152, A2105 (2005).

27. Z. Yang, B. J. Ingram, and L. Trahey, J. Electrochem. Soc., 161, A1127 (2014).

28. R. Younesi, M. Hahlin, M. Treskow, J. Scheers, P. Johansson, and K. Edström, J. Phys. Chem. C, 116, 18597 (2012).

29. R. A. Quinlan, Y.-C. Lu, Y. Shao-Horn, and A. N. Mansour, J. Electrochem. Soc., 160, A669 (2013)

30. R. Younesi, M. Hahlin, M. Roberts, and K. Edström, J. Power Sources, 225, 40 (2013).

31. S. S. Zhang, K. Xu, and T. R. Jow, J. Electrochem. Soc., 149, A1521 (2002).

32. J. Lei, L. Li, R. Kostecki, R. Muller, and F. McLarnon, J. Electrochem. Soc., 152, A774 (2005).

33. D. Ostrovskii, F. Ronci, B. Scrosati, and P. Jacobsson, J. Power Sources, 94, 183 (2001).

34. Z. Wang, X. Huang, and L. Chen, J. Electrochem. Soc., 151, A1641 (2004).

35. M. Onuki, S. Kinoshita, Y. Sakata, M. Yanagidate, Y. Otake, M. Ue, and M. Deguchi Onuki, J. Electrochem. Soc., 155, A794 (2008).

36. S. Malmgren, K. Ciosek, M. Hahlin, T. Gustafsson, M. Gorgoi, H. Rensmo, and K. Edström, Electrochim. Acta, 97, 23 (2013).

37. M. Gaberscek, J. Moskon, B. Erjavec, R. Dominko, and J. Jamnik, Electrochem. Solid-State Lett., 11, A170 (2008).

38. M. Park, X. Zhang, M. Chung, G. B. Less, and A. M. Sastry, J. Power Sources, 195, 7904 (2010).

39. O. Barbieri, M. Hahn, A. Herzog, and R. Kötz, Carbon N. Y., 43, 1303 (2005). 